\title{
FRET-trackable biodegradable HPMA copolymer-epirubicin conjugates for ovarian carcinoma therapy
}

\author{
Jiyuan Yang ${ }^{1}$, Rui Zhang ${ }^{1}$, D. Christopher Radford ${ }^{2}$, Jindřich Kopeček ${ }^{1,2, *}$
}

1Department of Pharmaceutics and Pharmaceutical Chemistry/CCCD, University of Utah, Salt Lake City, UT 84112, USA, 'Department of Bioengineering, University of Utah, Salt Lake City, UT 84112, USA

"Corresponding author: Jindřich Kopeček, Center for Controlled Chemical Delivery, 20 S $2030 \mathrm{E}$, BPRB 205B, University of Utah, Salt Lake City, UT 84112-9452, USA. Phone: (801) 581-7211; Fax: (801) 581-7848.

E-mail address: ïndrich.kopecek@utah.edu (J. Kopeček) 


\begin{abstract}
To develop a biodegradable polymeric drug delivery system for the treatment of ovarian cancer with the capacity for non-invasive fate monitoring, we designed and synthesized $\mathrm{N}$-(2hydroxypropyl)methacrylamide (HPMA) copolymer-epirubicin (EPI) conjugates. The polymer backbone was labeled with acceptor fluorophore Cy5, while donor fluorophores (Cy3 or EPI) were attached to HPMA copolymer side chains via an enzyme-cleavable GFLG linker. This design allows elucidating separately the fate of the drug and of the polymer backbone using fluorescence resonance energy transfer (FRET). The degradable diblock conjugate (2P-EPI) was synthesized by reversible addition-fragmentation chain transfer (RAFT) polymerization using a bifunctional chain transfer agent (Peptide2CTA). The pharmacokinetics (PK) and therapeutic effect of $2 \mathrm{P}$-EPI $(\mathrm{Mw} \sim 100 \mathrm{kDa})$ were determined in mice bearing human ovarian carcinoma A2780 xenografts. Compared to $1^{\text {st }}$ generation conjugate $(P-E P I, M w<50 k D a), 2 P-$ EPI demonstrated remarkably improved PK such as four-fold terminal half-life $(33.22 \pm 3.18 \mathrm{~h}$ for $2 \mathrm{P}$-EPI vs. $7.55 \pm 3.18 \mathrm{~h}$ for P-EPI), which is primarily attributed to the increased molecular weight of the polymer carrier. Notably, complete tumor remission and long-term inhibition of tumorigenesis (100 days) were achieved in mice $(n=5)$ treated with 2P-EPI. Moreover, in vitro cell uptake and intracellular drug release were determined via FRET intensity changes. The results establish a solid foundation for future in vivo tracking of drug delivery and chain scission of polymeric conjugates by FRET imaging.
\end{abstract}

Key words: $\mathrm{N}-(2-\mathrm{Hydroxypropyl)methacrylamide} \mathrm{(HPMA),} \mathrm{Epirubicin,} \mathrm{Ovarian} \mathrm{carcinoma,}$ FRET 


\section{Introduction}

Polymer-drug conjugates have a long history. The concept of polymer-drug conjugates was developed to address sub-optimal bioactivity and non-specificity of low molecular weight drugs in the human body [1-4]. Loading drugs on soluble macromolecules can improve pharmacokinetics and accumulation of drugs in solid tumors, resulting in enhanced therapeutic efficacy and reduced adverse side effects [5-7]. As the first example entering clinical trials for cancer treatment, (N-(2-hydroxypropyl)methacrylamide) (HPMA) copolymer-doxorubicin (DOX) conjugate demonstrated significant reduction of nonspecific toxicity. Maximum tolerated dose (MTD) of HPMA copolymer-DOX conjugate in humans was $320 \mathrm{mg} / \mathrm{m}^{2}$ of DOX equivalent, whereas MTD of free (unbound) DOX in humans is $60-80 \mathrm{mg} / \mathrm{m}^{2}$. The enhanced MTD of the polymer-bound DOX is primarily attributed to low uptake in heart tissue [8]. The use of polymeric drug delivery systems has become an established approach for improvement of cancer chemotherapy $[9,10]$. To gain more insight into the relationship between structure of polymer carrier and antitumor activity of polymer-conjugates, various fluorescent dyes have been exploited to investigate cellular uptake and drug release $[11,12]$.

Recently we designed $2^{\text {nd }}$ generation backbone-degradable HPMA copolymer carriers [1315]. The combination therapy of $A 2780$ human ovarian carcinoma xenografts with longcirculating HPMA copolymer-paclitaxel/gemcitabine conjugates showed distinct advantages over $1^{\text {st }}$ generation conjugates [16]. Similarly, the backbone degradable HPMA copolymers possessed enhanced efficacy (when compared to $1^{\text {st }}$ generation conjugates) in ovarian carcinoma xenografts in mice $[17,18]$ and in a rat osteoporosis model [19].

Epirubicin (EPI), the 4'-epimer of the anthracycline DOX, is an antineoplastic agent that inhibits DNA replication, transcription and repair by binding to nucleic acids [20]. Epirubicin has been regarded as one of the most active drugs for the patients with cancer, particularly with metastatic disease [21]. It has shown equivalent cytotoxic effects to DOX in human ovarian cancer cells, but decreased cardiotoxicity and myelotoxicity than DOX at equimolar doses [22]. Thus, epirubicin is thought to have a better therapeutic index than DOX. Recently, EPI has been bound to various polymer carriers to improve its properties and delivery. For example, dextran [23], polyethylene glycol (PEG) [24], dendritic PEG [25], human monoclonal antibodies [26], polyHPMA $[27,28]$ and polysialic acid [28] were used as (targetable) carriers.

Taking advantage of the inherent fluorescence of EPI, we synthesized $2^{\text {nd }}$ generation HPMA copolymer-EPI conjugates aiming to develop a biodegradable polymeric drug delivery system with the capacity for non-invasive fate monitoring. Fluorescence resonance energy transfer (FRET) was used as a tool to track chain scission of the conjugates and to elucidate separately the fate of the polymer backbone and the drug. The in vitro cytotoxicity, pharmacokinetics (PK), and in vivo antitumor activity of the conjugates were first evaluated on human ovarian carcinoma xenografts. The backbone of FRET polymers was labeled with Cy5, whereas model drug Cy3 or EPI was attached to HPMA copolymer backbone via an enzyme-cleavable GFLG linker. The cell uptake and drug release were analyzed by changes in FRET intensity.

\section{Materials and methods}

\subsection{Materials}

Common solvents methanol, acetonitrile, dimethylformamide (DMF), dichloromethane (DCM) were from Fisher Scientific (Pittsburgh, PA) as HPLC grade and used directly. Diisopropylethylamine (DIPEA), trifluoroacetic acid (TFA), papain (EC 3.4.22.2, from papaya latex) and cathepsin B (EC 3.4.22.1, from bovine spleen) were from Sigma-Aldrich (St. Louis, $\mathrm{MO}$ ). Epirubicin (EPI) was a kind gift from Prof. Kui Luo (Sichuan University, China). HATU was from AAPPTEC (Louisville, KY). 2,2-azobis[2-(2-imidazolin-2-yl)propane] dihydrochloride (VA- 
044) and 2,2-azobis(2,4-dimethyl valeronitrile) (V-65) were obtained from Wako Chemicals (Richmond, VA). ${ }^{125}$ lodine was from Perkin-Elmer (Waltham, MA). Cy3-/Cy5-NHS ester and Cy5-amine were purchased from Lumiprobe (Hallandale Beach, FL). Various monomers $\begin{array}{llll}\text { including } N \text {-(2-hydroxypropyl)methacrylamide } & \text { (HPMA) } & \text { [29], } & N \text { - }\end{array}$ methacryloylglycylphenylalanylleucylglycine $\quad$ (MA-GFLG-OH) [30], $\quad 3-(N-$ methacryloylglycylphenylalanylleucylglycyl) thiazolidine-2-thione (MA-GFLG-TT) [31], Nmethacryloyltyrosinamide (MA-Tyr- $\mathrm{NH}_{2}$ ) [32], 2-(N-methacryloylglycylphenylalanylleucylglycine)N'-Boc-ethylenediamine (MA-GFLG-NH-Boc) [16], and RAFT agents, 4-cyanopentanoic acid dithiobenzoate (CPA) [33] and peptide2CTA ( $N^{\alpha}, N^{\varepsilon}$-bis(4-cyano-4(phenylcarbonothioylthio)pentanoylglycylphenylalanylleucylglycyl)lysine) [15], were synthesized as previously described.

\subsection{Cell culture}

A2780 human ovarian cancer cells (ATCC) were maintained at $37^{\circ} \mathrm{C}$ in a humidified atmosphere containing $5 \% \mathrm{CO}_{2}$ in RPMI-1640 medium (Gibco) supplemented with $10 \%$ FBS and a mixture of antibiotics (100 units $/ \mathrm{mL}$ penicillin, $0.1 \mathrm{mg} / \mathrm{mL}$ streptomycin).

\subsection{Synthesis and characterization of HPMA copolymer conjugates}

\subsubsection{Synthesis of polymerizable derivative of epirubicin (MA-GFLG-EPI)}

$\mathrm{N}$-(methacryloylglycylphenylalanylleucylglycyl) epirubicin (MA-GFLG-EPI) was synthesized by the reaction of MA-GFLG-OH with EPI in DMF using HATU/DIPEA as coupling agent. In brief, EPI (54 mg, $0.1 \mathrm{mmol}$ ) was first dissolved in $0.2 \mathrm{~mL}$ DMF. MA-GFLG-OH (50 mg, 0.11 mmol) was dissolved in $0.5 \mathrm{~mL}$ DMF, followed by addition of HATU (38 $\mathrm{mg}, 0.1 \mathrm{mmol})$ and DIPEA (45 $\mu \mathrm{L}, 0.25 \mathrm{mmol})$. After activation at room temperature for $2 \mathrm{~min}$, MA-GFLG$\mathrm{OH} / \mathrm{HATU} / \mathrm{DIPEA}$ solution was added to the vial containing EPI solution. The system was kept stirring in dark overnight. The reaction solution $(10 \mu \mathrm{L}$, diluted with methanol) was then loaded onto an analytical column (Zorbax C18, 4.6×250 mm) and checked by HPLC. The peak of free EPI (15.34 min) disappeared, whereas a new peak showed up (20.14 min) indicating the reaction had finished. The solvent was removed by rotary evaporator under vacuum. The crude product was purified by column chromatography (silica gel $60 \AA$, 200-400 mesh) with elution 6:1 dichloromethane/methanol. A dark red powder was obtained after removal of the solvents with a yield of $70 \mathrm{mg}(70 \%)$. The structure of the monomer (MA-GFLG-EPI) was confirmed by MALDI ToF MS (LTQ-FT, ThermoElectron) $\left([\mathrm{M}+\mathrm{Na}]^{+} 1024.43\right)$, and the purity was verified by HPLC (Agilent 1100 series).

\subsubsection{Synthesis of HPMA copolymer-epirubicin conjugates $(P-E P I / 2 P-E P I$ and P-Tyr-EPI/2P- Tyr-EPI}

HPMA copolymer-epirubicin conjugates (P-EPI and 2P-EPI) were synthesized by the copolymerization of HPMA with MA-GFLG-EPI using VA044 as initiator and 4-cyanopentanoic acid dithiobenzoate (CTA) or Peptide2CTA as chain transfer agent, respectively. As an example, HPMA (138 mg, $0.965 \mathrm{mmol}$ ) and MA-GFLG-EPI (35 mg, $0.035 \mathrm{mmol}$ ) were dissolved in $0.3 \mathrm{~mL}$ methanol under $\mathrm{N}_{2}$ atmosphere. Peptide2CTA $(60 \mathrm{~L}$ with conc. $8.5 \mathrm{mg} / \mathrm{mL}$ in methanol, $[\mathrm{M}] /[\mathrm{CTA}]=1400)$ and VA044 at a molar ratio of $3: 1$ were added using a syringe. The ampoule was bubbled with $\mathrm{N}_{2}$ in ice bath for 5 min then sealed and polymerization was carried out at $40^{\circ} \mathrm{C}$ for $24 \mathrm{~h}$. The copolymer was precipitated in acetone. The resultant orange-color copolymer was re-dissolved in methanol and re-precipitated in acetone to remove unreacted monomers. The dithiobenzoate end group was replaced by radical-induced end-modification 
using excess of $\mathrm{V}-65$ in methanol at $55{ }^{\circ} \mathrm{C}$ for $2 \mathrm{~h}$. The final product (2P-EPI) was isolated by precipitation and dried under vacuum at room temperature with yield of $80 \mathrm{mg} \mathrm{(50 \% ).} \mathrm{Similarly,}$ P-EPI was obtained when CTA was used as RAFT agent with [M]/[CTA] $=550$ (Scheme 1).

The molecular weight and molecular weight distribution of the conjugates were determined by size-exclusion chromatography (SEC) on an ÄKTA FPLC system (GE healthcare) equipped with miniDAWN and OptilabEX detectors (Wyatt) with acetate/30\% acetonitrile $(\mathrm{pH} \mathrm{6.5)} \mathrm{as}$ mobile phase. Superose $6 \mathrm{HR} 10 / 30$ column was used. The drug content in conjugates was determined by enzyme cleavage of free drug from polymer side chain GFLG linker using papain according to the procedure described previously [15].

To synthesize a radioisotope ${ }^{125}$ I labeled conjugate, comonomer $\mathrm{MA}-\mathrm{Tyr}_{\mathrm{N}} \mathrm{NH}_{2}(1.5 \% \mathrm{molar}$ ratio in feed) was added and the same procedure shown above was used to produce P-TyrEPI/2P-Tyr-EPI.
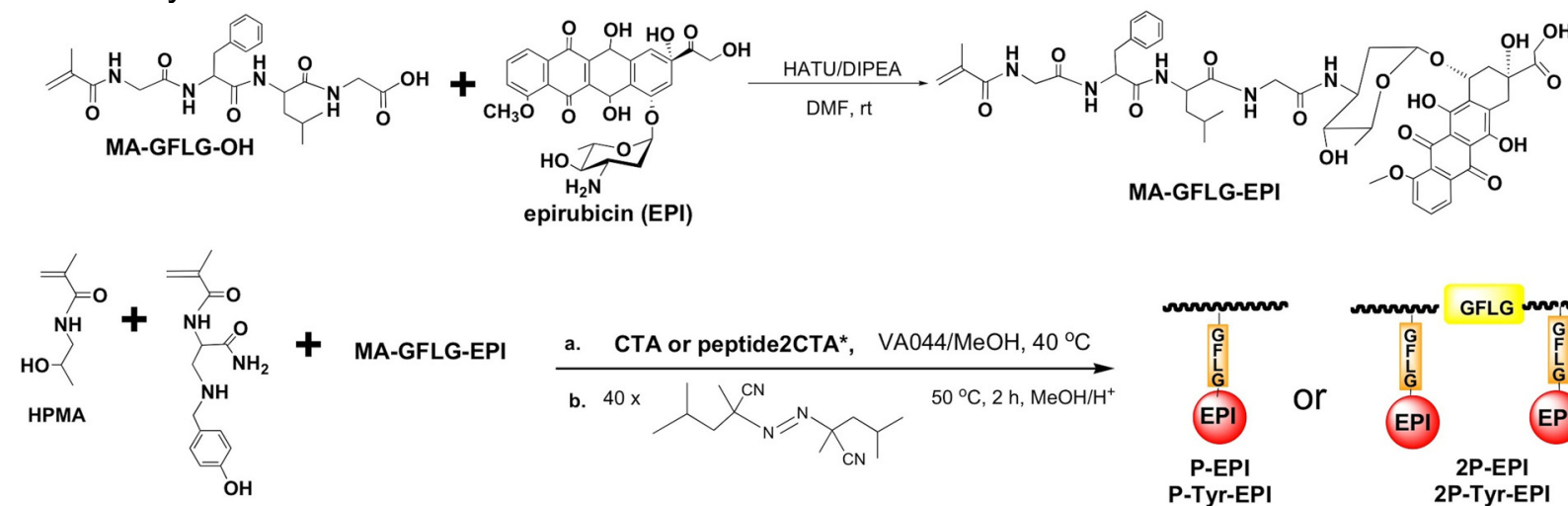

MA-Tyr-NH ${ }_{2}$ for ${ }^{125}$ l labeling
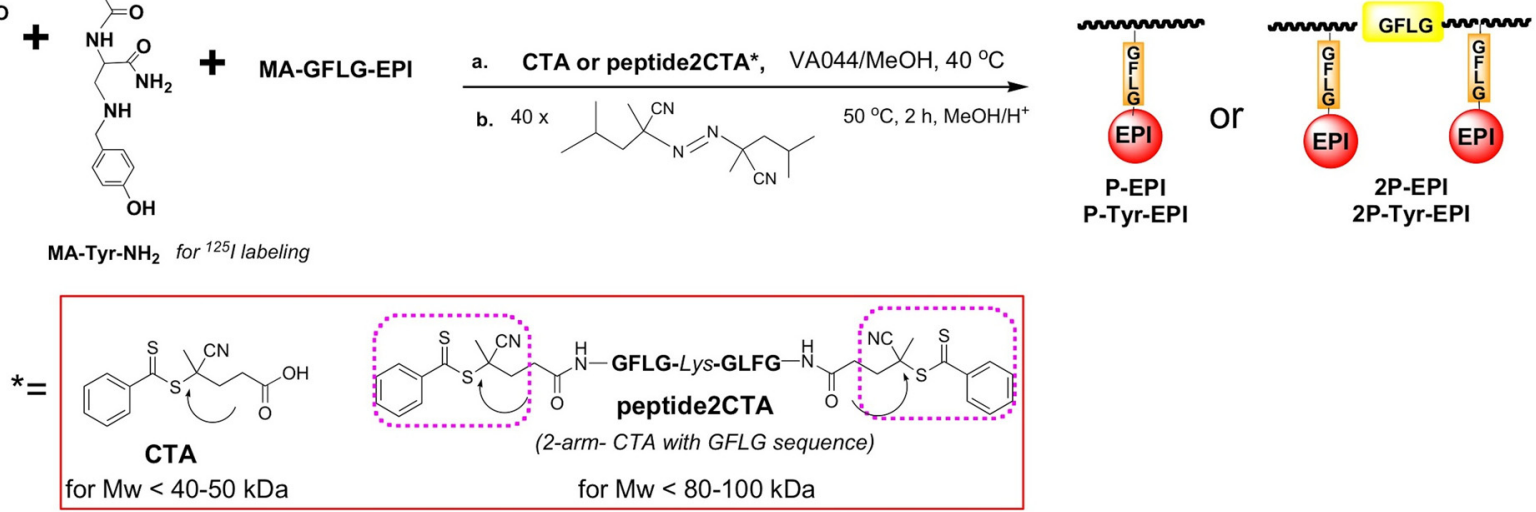

Scheme 1. Synthesis of HPMA copolymer-epirubicin conjugates

\subsubsection{Synthesis of polymer conjugates containing fluorophore Cy3 and/or Cy5}

To synthesize polymer conjugates suitable for FRET evaluation, P-Cy3-Cy5/2P-Cy3-Cy5, the polymer precursor containing side chain thiazolidine-2-thione (TT) and GFLG linker terminated with protected amino group was first synthesized by RAFT copolymerization of the amino-protected monomer (MA-GFLG-NH-Boc [16]), HPMA and MA-GG-TT (Scheme 2A). After chain end-modification, the content of TT groups in the copolymer was determined by UV $\left(\varepsilon_{305}=10,900 \mathrm{M}^{-1} \mathrm{~cm}^{-1}\right.$ in methanol) [31]. Cy5- $\mathrm{NH}_{2}$ was dissolved in DMSO and reacted with polymer precursor. Unbound dye was removed using PD10 column. To incorporate the second dye, Cy3, the polymer was dissolved in water followed by addition of trifluoroacetic acid. The sample was kept stirring in ice-bath for $30 \mathrm{~min}$, then condensed under reduced pressure and precipitated in precooled ether/acetone. The side-chain amino content in the deprotected polymer was analyzed by ninhydrin assay. Cy3-NHS was used to attach Cy3 to the polymer backbone via GFLG enzyme-cleavable linker. The content of Cy3 and Cy5 in the polymer chain was determined via UV-vis spectroscopy.

As control, HPMA copolymers containing fluorophore Cy3 or Cy5 (P-Cy3 or P-Cy5) were synthesized by polymer analogous reaction of HPMA polymer precursor containing pendant amino groups with Cy3-/Cy5-NHS ester (Scheme 2B). Free dye was removed using PD10 
column (Amersham Biosciences). The content of Сy3/Cy5 in polymer conjugates was determined via UV-vis spectroscopy (Varian Cary 400 Bio UV-visible spectrophotometer).
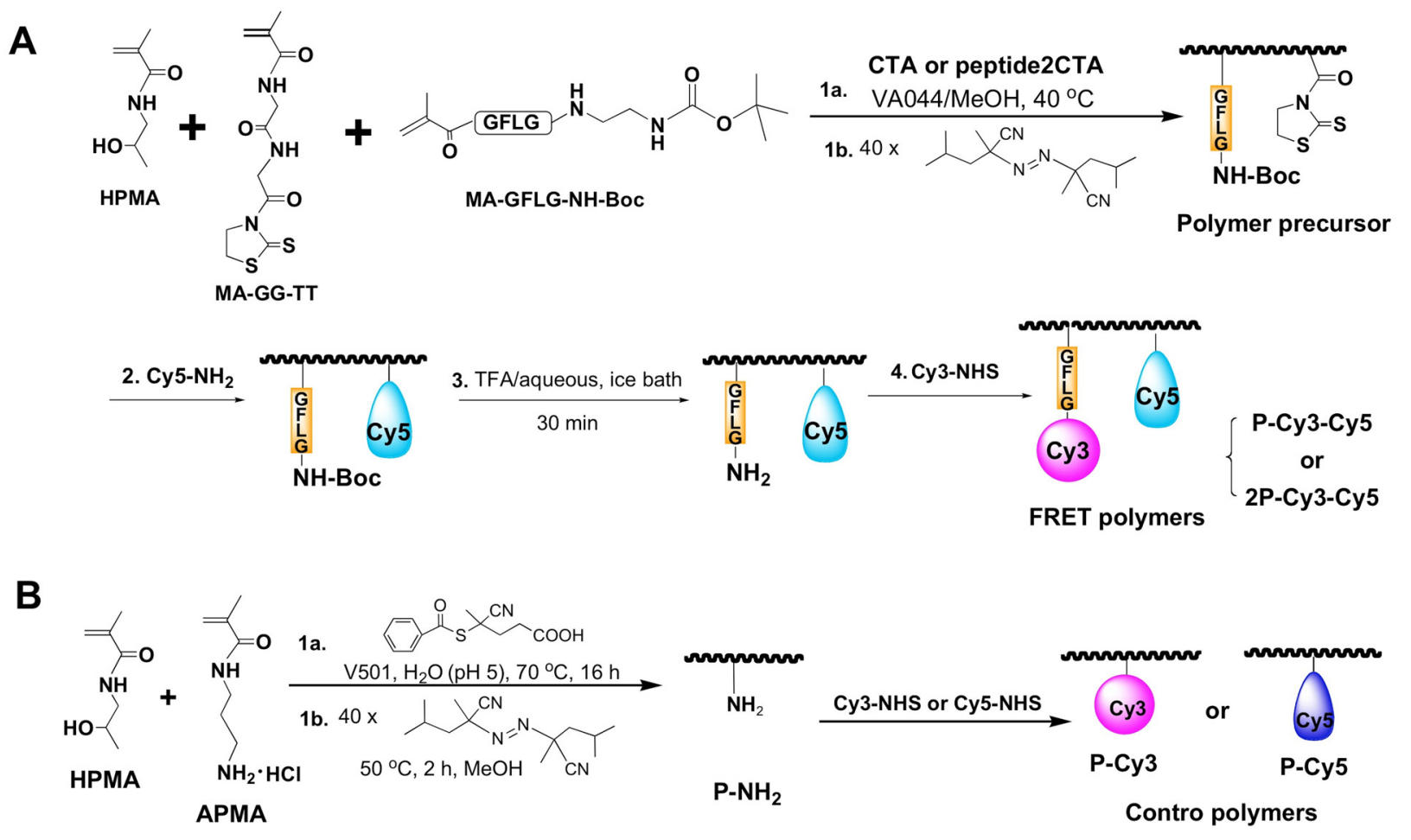

Scheme 2. Synthesis of polymer conjugates containing fluorophores

\subsubsection{Synthesis of HPMA copolymer-epirubicin conjugate containing fluorophore Cy5}

FRET polymer P-EPI-Cy5 was synthesized in two steps (Scheme 3): First, RAFT copolymerization of HPMA (134 mg, $0.94 \mathrm{mmol}$ ), MA-GFLG-EPI (33 mg, $0.035 \mathrm{mmol}$ ) and MAGG-TT $(7.5 \mathrm{mg}, 0.025 \mathrm{mmol})$ was conducted in methanol at $40{ }^{\circ} \mathrm{C}$ as described above. The dithiobenzoate end group was removed by addition of $40 \mathrm{x} \mathrm{V65}$ to the polymer solution at $55^{\circ} \mathrm{C}$ for $2 \mathrm{~h}$. The TT group was then aminolyzed by Cy5- $\mathrm{NH}_{2}$. The free dye was removed using PD10 column. The final contents of EPI and Cy5 were determined by UV-vis spectroscopy.

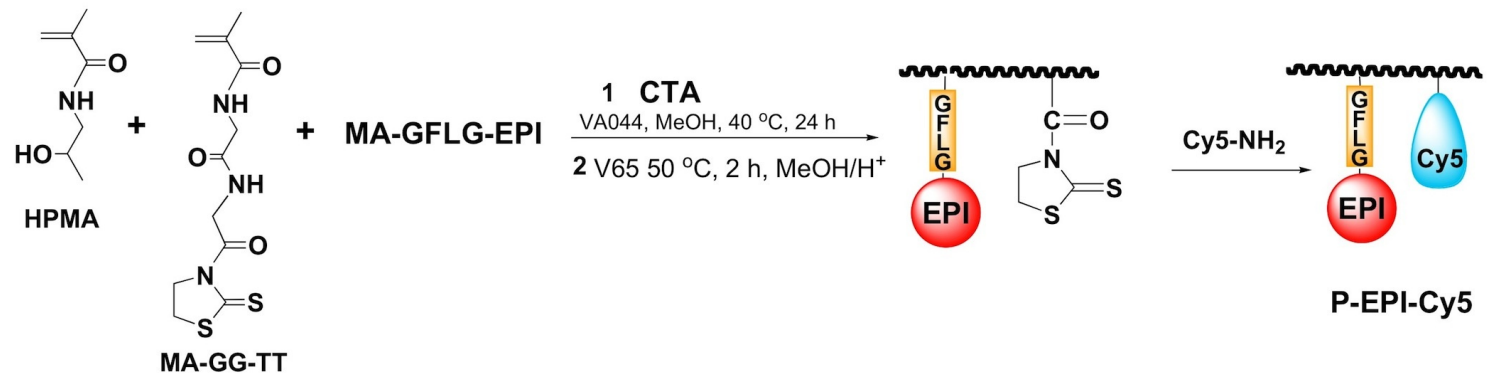

Scheme 3. Synthesis of polymer conjugates containing epirubicin and Cy5 (P-EPI-Cy5)

\subsection{FRET measurements}

The concentration of fluorophore-labeled conjugate solution was first determined by UV-vis spectroscopy. Typically, $1.5 \mathrm{mg} / \mathrm{mL}$ conjugate in methanol was scanned within range of $400-800$ $\mathrm{nm}$. The solution was further diluted into $\sim 100 \mathrm{~g} / \mathrm{mL}$, and the fluorescence intensity of each 
sample was measured in duplicates using Infinite M1000 PRO (TECAN) with excitation wavelengths of $445 \mathrm{~nm}$ for EPI (P-EPI), $548 \mathrm{~nm}$ for Cy3 (P-Cy3) and $646 \mathrm{~nm}$ for Cy5 (P-Cy5), respectively. For FRET measurements, the donor was excited at $520 \mathrm{~nm}$ for Cy3 [34] and 445 $\mathrm{nm}$ for EPI; the emission spectra of the donor-acceptor were recorded at the range of 400 to $800 \mathrm{~nm}$.

To compare the fluorescence intensity changes of the conjugate P-Cy3-Cy5 before and after cleavage of the donor Cy3, the conjugate was incubated in Mcllvaine's buffer $(50 \mathrm{mM}$ citrate $/ 0.1 \mathrm{M}$ phosphate, $\mathrm{pH} 6)$ in the presence of papain $(5 \mathrm{mg} / \mathrm{mL}$, preactivated with $10 \mathrm{mM}$ glutathione) at $37^{\circ} \mathrm{C}$ for $1 \mathrm{~h}$. The cleaved conjugate was diluted into methanol and determined with Ex $520 \mathrm{~nm}$.

\subsection{FRET change measurement in cancer and normal cells}

To determine the cathepsin $\mathrm{B}$ dependence of drug release capability in our conjugates, FRET model conjugates, P-Cy3-Cy5 and 2P-Cy3-Cy5, were incubated with A2780 ovarian cancer cells (cathepsin B over-expressing) and NIH3T3 normal cells (cathepsin B low expression). The cells were first incubated with the conjugate (P-Cy3-Cy5 or 2P-Cy3-Cy5) at $37^{\circ} \mathrm{C}$ for $4 \mathrm{~h}$, then cells were washed with fresh medium and subsequently cultured in fresh medium without conjugate for another 8 or $20 \mathrm{~h}$. Cell lysates at different time intervals were measured by fluorescence spectrometer. FRET ratio $=I_{\text {Cy } 3} / I_{\text {FRET }}$, where $I_{\text {Cy3 }}$ and $I_{\text {FRET }}$ are the fluorescence intensity at $562 \mathrm{~nm}$ and $664 \mathrm{~nm}$, respectively (excitation $520 \mathrm{~nm}$ ). The data were presented as mean \pm standard deviation $(n=3)$.

\subsection{Confocal microscopy of FRET changes in A2780 cancer cells}

To visualize the FRET changes in cancer cells, A2780 cells were first incubated with conjugate $\mathrm{P}-\mathrm{Cy} 3-\mathrm{Cy} 5$ at $37^{\circ} \mathrm{C}$. After $4 \mathrm{~h}$ incubation, the cells were washed and fresh medium was added. Then a portion of treated cells was fixed with $4 \%$ paraformaldehyde immediately while the other cells were incubated for another $20 \mathrm{~h}$ and then were fixed. The fixed cells were observed under confocal microscope using the standard acceptor Cy5 photobleaching FRET method (the cells were exposed to high excitation intensity at an excitation wavelength of 646 $\mathrm{nm}$ for a $20 \mathrm{~min}$ period. In this experiment, both pre-bleach and post-bleach images were collected).

\subsection{EPI release inside cultured cells}

The release of drug EPI from Cy5-labeled polymeric conjugate was determined using FRET, with EPI serving as the donor fluorophore, and Cy5 as the acceptor. The conjugate P-EPI-Cy5 was incubated with $\mathrm{A} 2780$ cells at $37^{\circ} \mathrm{C}$ for $4 \mathrm{~h}$. Then the treated cells were cultured in fresh medium for another $20 \mathrm{~h}$. The cell lysate was measured by fluorescence spectrometer, before and after the $20 \mathrm{~h}$ additional culture. The "relative" FRET efficiency, also known as the FRET ratio, was calculated with the following equation FRET ratio $=I_{E P I} / I_{F R E T}$, where $I_{E P I}$ and $I_{F R E T}$ are the fluorescence intensity at $590 \mathrm{~nm}$ and $664 \mathrm{~nm}$, respectively (excitation $490 \mathrm{~nm}$ ).

\subsection{Cell uptake study}

Cellular uptake of the EPI and its conjugates (P-EPI and 2P-EPI) was analyzed using flow cytometry. A2780 human ovarian cancer cells $\left(2 \times 10^{5}\right)$ were seeded in 6 -well plates. After $24 \mathrm{~h}$ culture, the cells were treated with free EPI, P-EPI, or 2P-EPI (EPI concentration: $100 \mathrm{nM}$ ) for 6 or $24 \mathrm{~h}$. Untreated cells served as a negative control for background fluorescence. Thereafter, the cells were harvested and washed. An average of $1 \times 10^{4}$ cells was determined using flow 
cytometry (BD Biosciences) and FlowJo software (Tree star). EPI uptake was analyzed based on the EPI fluorescence intensity $(n=3)$.

\subsection{In vitro cytotoxicity study}

The cytotoxicity of free drug EPI and its polymeric conjugates (P-EPI, 2P-EPI) against A2780 human ovarian cancer cells was measured by CCK-8 assay (Dojindo). The cells were seeded in 96 -well plates at the density of 10,000 cells/well in RMPI-1640 media containing $10 \%$ FBS. The cells were washed after $24 \mathrm{~h}$, then incubated with media containing the drug EPI or its polymeric conjugates (P-EPI, 2P-EPI) at a series of drug concentrations. After $48 \mathrm{~h}$ of incubation, the number of viable cells was estimated using CCK-8 kit according to manufacturer's protocol. In brief, medium was discarded and replaced with $100 \mu \mathrm{L}$ fresh growth medium in each well, followed by the addition of $50 \mu \mathrm{L} 5 \times$ diluted CCK-8 solution. Dehydrogenase activities in live cells converted the water-soluble tetrazolium salt WST-8 into a soluble yellow-color formazan dye. After the incubation of cells at $37^{\circ} \mathrm{C}, 5 \% \mathrm{CO}_{2}$ for $2 \mathrm{~h}$, the absorbance was measured using a microplate reader at $450 \mathrm{~nm}$ (630 nm as reference). Untreated control cells were set as $100 \%$ viable.

\subsection{Radiolabeling and pharmacokinetics study}

HPMA copolymer-EPI conjugates containing tyrosinamide were reacted with $\mathrm{Na}^{125}$ I (Perkin Elmer) at room temperature in $0.01 \mathrm{M}$ phosphate buffer containing chloramine-T for 30 min and then purified with PD-10 columns (GE Healthcare). The specific activity of the hot samples was in the range $40-60 \mu \mathrm{Ci} / \mathrm{mg}$. The ${ }^{125}$ I labeling of polymer conjugates was conducted immediately before use. After radiolabeling, 6- to 8-week-old healthy female nude mice (22-25 g; Charles River Laboratories) were intravenously injected $0.5 \mathrm{mg}(20 \mu \mathrm{Ci} /$ mouse $){ }^{25}$ I-labeled HPMA copolymer-drug conjugates (P-EPI and 2P-EPI, five mice per group). At predetermined intervals, blood samples $(10 \mu \mathrm{L})$ were taken from the tail vein, and the radioactivity of each sample was measured with Gamma Counter (Packard). The blood pharmacokinetic parameters for the radiotracer were analyzed using a two-compartmental model with WinNonlin 5.0.1 software (Pharsight).

\subsection{Tumor model}

All animal studies were carried out in accordance with the University of Utah IACUC guidelines under approved protocols. A2780 human ovarian cancer cells $\left(5 \times 10^{6}\right)$ in $100 \mu \mathrm{L}$ of phosphate buffered saline were subcutaneously inoculated in right flank of 6- to 8-week-old syngeneic female nude mice (22-25 g, Charles River Laboratories). When tumor reached approximately $4-5 \mathrm{~mm}$ in diameter (average 3 weeks after inoculation) treatment started.

\subsection{In vivo antitumor activity}

Female nude mice bearing subcutaneous A2780 ovarian tumors were randomly assigned to four groups ( $n=5$ for each group). P-EPI and 2P-EPI were administered via tail vein with dose $5 \mathrm{mg} / \mathrm{kg}$ EPI equivalent on day 0,4 , and 8 . Free drug EPI was also used for comparison. The mice in the control group were treated with saline. The day that mice received EPI or its conjugates treatment was set as day 0 . The tumor size was measured to monitor the tumor growth. The tumor volume at day 0 was normalized to $100 \%$. All subsequent tumor volumes and body weight were then expressed as the percentage relative to those at day 0 . Mice were sacrificed at signs of sickness such as body weight loss $>20 \%$. Otherwise mice were sacrificed at 100 days. 


\subsection{Statistical analysis}

The Student's t test was used to test differences in therapeutic efficiency, cell uptakes, pharmacokinetic parameters, and toxicity among different conjugates. Comparison among groups was performed using one-way ANOVA. The significance level was set at 0.05 .

\section{Results and discussion}

\subsection{Synthesis of HPMA copolymer-epirubicin conjugates}

As an isomer of DOX, EPI has been reported to have different metabolic degradation and faster clearance from plasma after i.v. injection. As a result, EPI has less side effects compared with DOX at doses producing equivalent antitumor effects [35]. EPI therefore has been nanosized to various formulations such as micelles [36], liposomes [37], nanoparticles [38,39], and, most interesting for us, water-soluble conjugates to improve its therapeutic index. In general, polymer-EPI conjugates were produced via polymeranalogous reaction in which EPI is attached to polymer through active ester [27] or in the presence of coupling agents [25,28]. Here we report a different way to synthesize the conjugates - RAFT copolymerization. The polymerizable EPI derivative was synthesized first, and then copolymerized with HPMA with option of using MA-Tyr- $\mathrm{NH}_{2}$ for isotope labeling. The major advantage of this approach is reproducibility with predetermined molecular weight and narrow polydispersity. In addition, the polymer is relatively pure without detectable free drug (Figure S1). Previously we have reported synthesis of long-circulating 2P-PTX and 2P-GEM in one step using a two-arm enzymecleavable chain transfer agent [16]. To assess this universal approach, we synthesized the $1^{\text {st }}$ generation and $2^{\text {nd }}$ generation HPMA copolymer-EPI conjugates; their molecular weight (including molecular weight distribution) and drug content are listed in Table 1.

Table 1. Characterization of HPMA copolymer-epirubicin conjugates

\begin{tabular}{ccccc}
\hline & Mn (kDa) & Mw (kDa) & Mw/Mn & EPI \% (wt) \\
\hline P-EPI & 39 & 43 & 1.10 & 7.4 \\
P-Tyr-EPI & 26 & 28 & 1.08 & 6.5 \\
2P-EPI & 76 & 106 & 1.39 & 5.9 \\
2P-Tyr-EPI & 61 & 84 & 1.38 & 6.4 \\
\hline
\end{tabular}

\subsection{Cell uptake and in vitro cytotoxicity}

The cell uptake of the conjugates (P-EPI and 2P-EPI) was analyzed using flow cytometry with EPI fluorescence signal. The free drug EPI was used as a control. A2780 human ovarian cancer cells were incubated with different EPI formulations, respectively. Free EPI showed a higher cell uptake than the two conjugates. This difference is likely due to their distinct entry pathways - diffusion (free drugs) vs. endocytosis (conjugates). In addition, the cytotoxicity of free EPI and its HPMA copolymer conjugates (P-EPI and 2P-EPI) against A2780 human ovarian cancer cells was determined. Figure $1 \mathrm{~A}$ shows the representative cell-growth inhibition curves. Overall, free drug EPI and its conjugates (P-EPI, 2P-EPI) showed a dose-dependent cytotoxicity against $\mathrm{A} 2780$ cells. On the basis of the $\mathrm{IC}_{50}$ values (Figure 1B), both HPMA copolymer-EPI 
conjugates had less in vitro cytotoxicity than free EPI, due to the different mechanism of cell uptake $[4,7]$.

A

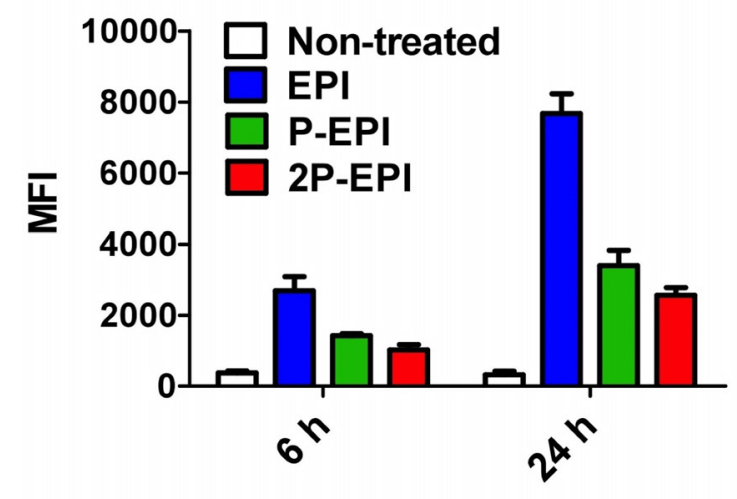

B

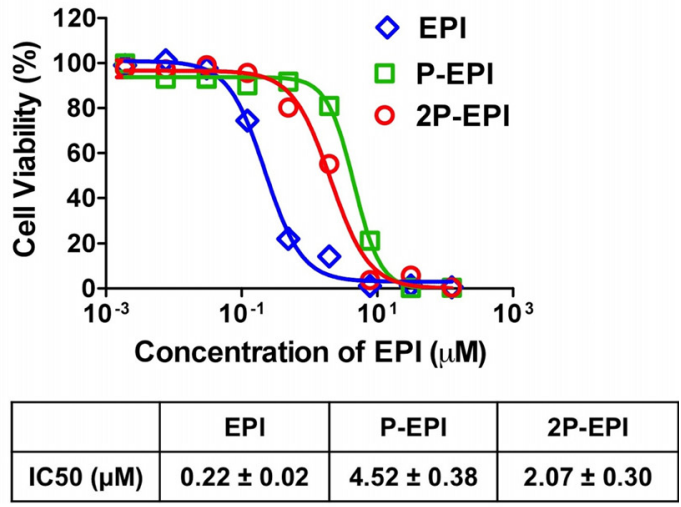

Figure 1. Cell uptake and cytotoxicity of free drug EPI and its conjugates (P-EPI, 2P-EPI) in A2780 human ovarian cancer cells. (A) Flow cytometry analysis of cell uptake in the A2780 cells incubated with medium alone (non-treated), free EPI, or its conjugates (P-EPI, $2 \mathrm{P}-\mathrm{EPI}$ ) at $37^{\circ} \mathrm{C}$ for 6 and $24 \mathrm{~h}$. MFI, mean fluorescence intensity. (B) In vitro cytotoxicity of free drug EPI and its HPMA conjugates (P-EPI, 2P-EPI) toward A2780 human ovarian carcinoma cells. The data are presented as mean \pm standard deviation $(n=3-4)$.

\subsection{Pharmacokinetic study of ${ }^{125}$ /-labeled conjugates}

It has been reported that conjugation of free drug to HPMA polymer carrier markedly slows its blood clearance [40]. For example, the fast initial clearance of DOX $\left(t_{1 / 2}\right)$ is 4 min, however, there was still $55 \%$ polymer-bound drug in circulation $1 \mathrm{~h}$ after injection of P-DOX (Mw $25 \mathrm{kDa}$ ) [40]. In this study, we compared pharmacokinetic profiles of $1^{\text {st }}$ generation conjugate $(P-(T y r)-E P I$, $\mathrm{Mw} 28 \mathrm{kDa})$ and $2^{\text {nd }}$ generation conjugate $(2 \mathrm{P}-$ (Tyr)-EPI, Mw $84 \mathrm{kDa}$ ) to highlight the effect of molecular weight on plasma concentration and circulation time. Tyrosine moiety was inserted into the conjugates for radiolabeling $\left({ }^{125} \mathrm{I}\right)$ in order to enhance accuracy and sensitivity of the analysis. The blood radioactivity-time profiles were determined and illustrated in Figure 2. The pharmacokinetic parameters of the two conjugates in mice are listed in Table 2, and the previously reported half-lives of 2P-PTX/P-PTX and 2PGEM/P-GEM are cited here for comparison [16]. Higher Mw 2P-EPI conjugate showed a longer terminal half-life $(33.22 \mathrm{~h})$ than low $\mathrm{Mw}$ conjugate P-EPI (7.55 h). 2P-EPI (AUC=1060.48 \%ID/mL) had a 10-fold higher systemic exposure than PEPI $(110.10 \% \mathrm{ID} / \mathrm{mL}) \quad(p<0.001)$. The increased exposure of $2 \mathrm{P}-\mathrm{EPI}$ is mainly attributed to its

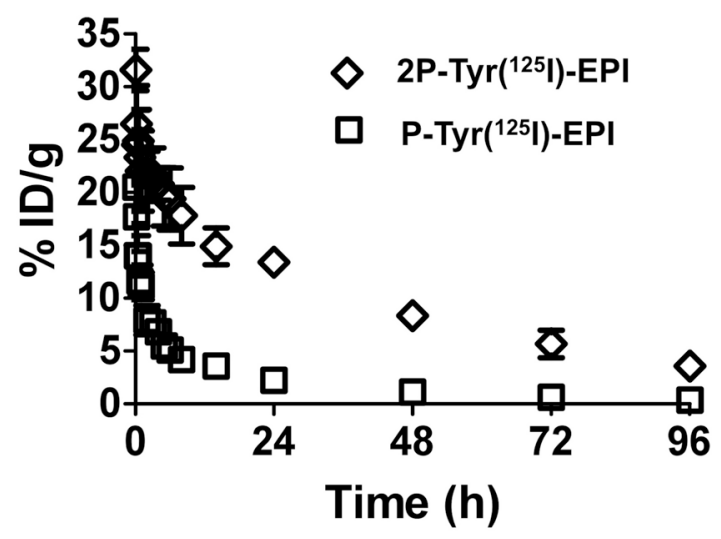

Figure 2. Pharmacokinetic profiles of ${ }^{125} \mathrm{I}-$ labeled conjugates P-EPI and 2P-EPI in mice. The data represent the mean radioactivity expressed as a percentage of the injected dose per gram of blood $(n=5)$. EPI: $0.09 \mathrm{~mL} / \mathrm{h}$ vs. P-EPI: $0.91 \mathrm{~mL} / \mathrm{h})(\mathrm{p}<0.001)$. Taken all together, the $2^{\text {nd }}$ generation conjugate $2 \mathrm{P}$-EPI having an increased Mw possesses an improved pharmacokinetic profile. 
Table 2. Comparison of pharmacokinetic parameters for ${ }^{125}$-labeled conjugates in mice

\begin{tabular}{|c|c|c|c|c|c|c|}
\hline & P-EPI & P-PTXa & P-GEMa & 2P-EPI & 2P-PTXa & 2P-GEMa \\
\hline $\mathrm{T}_{1 / 2, \alpha}(\mathrm{h})$ & $0.33 \pm 0.07$ & $0.88 \pm 0.11$ & $0.26 \pm 0.02$ & $0.18 \pm 0.06$ & $1.13 \pm 0.13$ & $1.45 \pm 0.36$ \\
\hline $\mathrm{T}_{1 / 2, \beta}(\mathrm{h})$ & $7.55 \pm 1.55$ & $13.30 \pm 1.28$ & $6.36 \pm 0.66$ & $33.22 \pm 3.18$ & $37.90 \pm 3.55$ & $32.07 \pm 2.50$ \\
\hline AUC (\%ID $\mathrm{h} / \mathrm{mL}$ blood) & $110.10 \pm 14.06$ & $420.95 \pm 26.05$ & $108.66 \pm 6.74$ & $1060.48 \pm 88.83$ & $1206.42 \pm 85.97$ & $1481.23 \pm 83.06$ \\
\hline $\mathrm{CL}(\mathrm{mL} / \mathrm{h})$ & $0.91 \pm 0.12$ & $0.24 \pm 0.01$ & $0.92 \pm 0.06$ & $0.09 \pm 0.01$ & $0.08 \pm 0.01$ & $0.07 \pm 0.004$ \\
\hline MRT (h) & $10.34 \pm 2.09$ & $18.25 \pm 1.71$ & $8.49 \pm 0.88$ & $47.79 \pm 4.57$ & $52.86 \pm 4.95$ & $45.39 \pm 3.43$ \\
\hline Vss (mL) & $9.39 \pm 0.82$ & $4.34 \pm 0.16$ & $7.82 \pm 0.38$ & $4.51 \pm 0.11$ & $4.38 \pm 0.16$ & $3.06 \pm 0.10$ \\
\hline
\end{tabular}

Although individual drugs (EPI, PTX, and GEM) have different metabolism and clearance time [41], the new generation conjugate 2P-EPI showed significant improved pharmacokinetics with parameters similar to 2P-PTX and 2P-GEM, such as terminal half life, total body clearance, and steady-state volume of distribution (Table 2), which indicates conjugation of drug to polymer carrier can improve its stability in plasma, and the elimination rate of the conjugates is primarily determined by the polymer carrier.

\subsection{In vivo anti-tumor activity}

The therapeutic potential of the backbone degradable long-circulating HPMA copolymer-EPI conjugate (2P-EPI) was evaluated in female nude mice bearing A2780 human ovarian carcinoma xenografts. The mice were intravenously injected with three doses of $5 \mathrm{mg} / \mathrm{kg}$ EPI equivalent on days 0,4 , and 8 . Free drug EPI and the $1^{\text {st }}$ generation conjugate P-EPI were also administered for comparison. Tumor growth was closely monitored during and after treatment. At day 20, complete tumor regression was achieved in the five mice treated with conjugate 2PEPI (Figure 3); the tumors treated with P-EPI shrank to $80 \pm 37 \%$ of the initial size. In contrast, free drug EPI at equivalent doses only slightly delayed tumor growth when compared with saline (control), and mice had to be sacrificed on day 20 as the tumor had reached $1772 \pm 840 \%$ of the baseline. However, there was no significant difference between treatment with 2P-EPI and PEPI until day 35 when tumor started regrowth in P-EPI group, and four of the tumors grew back to $\sim 1200 \%$ at day $80(p<0.01)$ (Figure 3$)$. On the contrary, no observable tumor was detected in the mice treated with $2 \mathrm{P}-\mathrm{EPI}$ at day 100 . These results demonstrate the importance of long-term experiments for evaluation of tumor growth inhibitory effect. The results also indicated that 2P$\mathrm{EPI}$ is highly superior to both P-EPI and free EPI. The complete tumor regression and long-term inhibition of tumorigenesis by $2 \mathrm{P}$-EPI treatment are attributed to long circulation time and sufficient extravasation of the conjugates at the tumor site by the enhanced permeability and retention (EPR) effect. In addition, this result also suggests that $2 \mathrm{P}$-EPI conjugate may be able to arrest both tumor progenitor cells and differentiated cells as we observed in another scenarios [42].

For safety concern, body weight of the mice was closely recorded during and after treatment (Figure S2). The body weights of the mice temporarily decreased (less than 10\%) when P-EPI and 2P-EPI were administered as multiple dosages but recovered gradually and remained stable after withdrawal, which suggests the doses used were tolerable. 

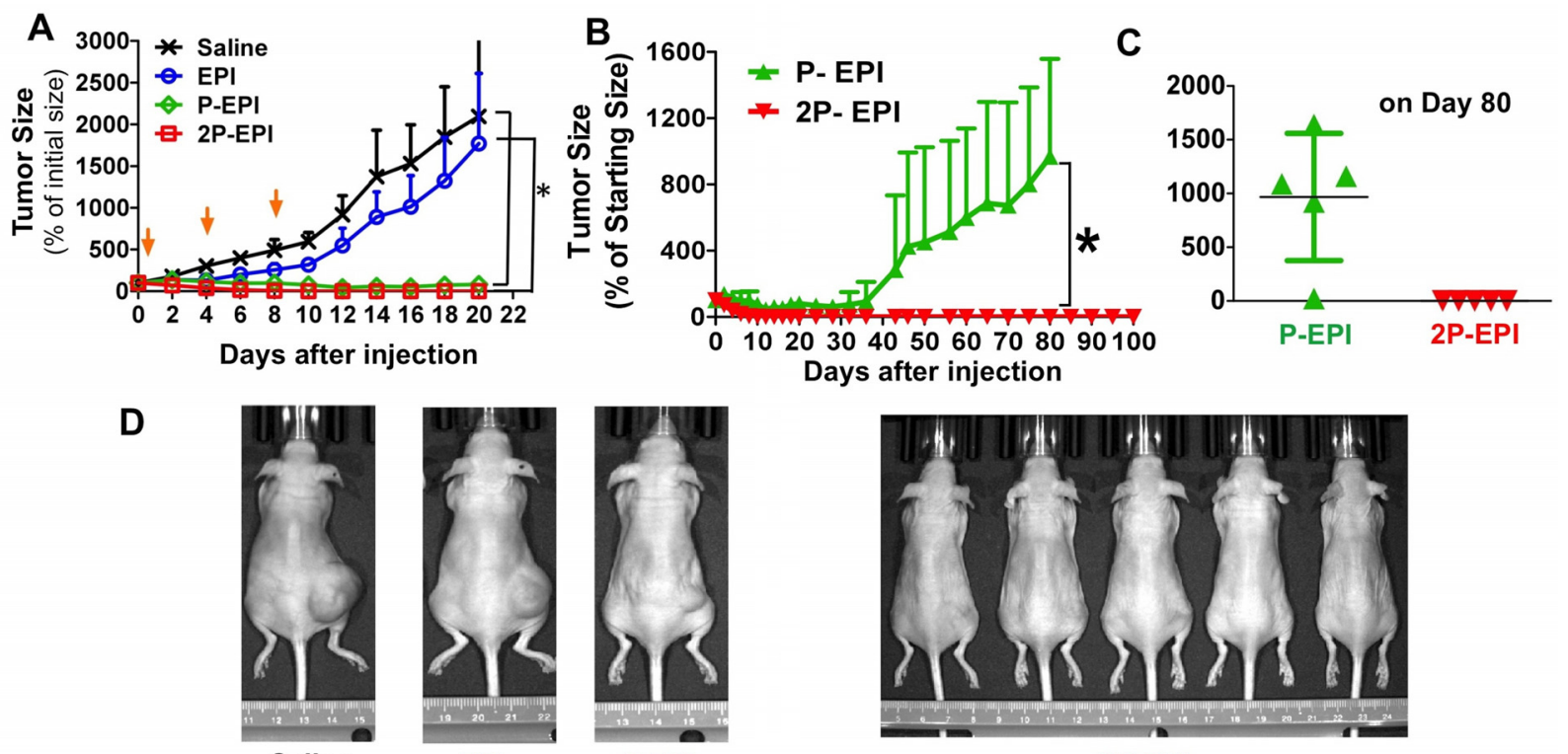

P-EPI

2P-EPI

Figure 3. Comparison of in vivo anti-tumor activity on female nude mice bearing A2780 human ovarian carcinoma xenografts. (A) The mice were intravenously injected with 3 doses of EPI or HPMA copolymer-EPI conjugates (P-EPI and 2P-EPI). Free drug and untreated groups were stopped on day 20 due to large size of tumors. (B) Long-term monitoring of tumor growth in conjugate treatments. (C) The tumor size on day 80 of the polymer conjugates, and (D) End point photographs of tumor-bearing mice from variable treatments.

\subsection{Potential to track chain degradation and intracellular drug release via FRET}

Similar to DOX, the fluorescence signal from EPI has been used for cellular uptake studies $[39,43]$. However, the polymer conjugation can affect the fluorescence emission [28]. Consequently, the data only from drug fluorescence may be misinterpreted.

Herein we propose to use FRET imaging as a tool to monitor drug release from HPMA copolymer conjugates. Initially, we designed and prepared a HPMA copolymer conjugate containing a popular FRET pair Cy3/Cy5 the donor fluorophore Cy3 was attached to HPMA polymer backbone as model drug via a cleavable (by lysosomal proteases) tetrapeptide linker Gly-Phe-Leu-Gly (GFLG), while the acceptor Cy5 was directly labeled on the HPMA backbone as a tag (Figure 4A, Scheme 2). To characterize its FRET property, the conjugate was determined using fluorescence spectrometry before and after exposure to papain, a thiol proteinase with specificity similar to lysosomal cathepsin B. Ex $520 \mathrm{~nm}$ was selected to minimize direct emission of Cy5. As shown in Figure 4B, detectable FRET occurred in the original non-treated conjugate, but not in the same conjugate incubated with papain. Loss of FRET was due to the cleavage of the linker GFLG by enzyme, and consequently, the release of Cy3 from backbone.

The FRET property of conjugates (P-Cy3-Cy5 and 2P-Cy3-Cy5) was further elucidated in living cells. Human ovarian cancer A2780 cells that overexpress cathepsin B were incubated with the FRET conjugate, and NIH3T3 mouse fibroblast cells (low cathepsin B expression) were used as control. The release of model drug Cy3 will result in decrease of FRET intensity that can be investigated via cell lysis using fluorescence spectrometry. According to the previous reports [44-46], the ratio, $I_{\mathrm{Cy}_{3}} / \mathrm{I}_{\mathrm{FRET}}$, was calculated to quantify the FRET change, where $\mathrm{I}_{\mathrm{Cy} 3}$ and $\mathrm{I}_{\text {FRET }}$ are the fluorescence intensity at $562 \mathrm{~nm}$ and $664 \mathrm{~nm}$, respectively (excitation $520 \mathrm{~nm}$ ). For the conjugate P-Cy3-Cy5, the ratio in medium alone was 2.35, and in initial stock was 1.97. 
When the conjugate was incubated with A2780 cancer cells, the ratio increased to 2.71 at $4 \mathrm{~h}$, then gradually increased to 3.99 at $12 \mathrm{~h}$ and 5.25 at $24 \mathrm{~h}$, whereas in NIH3T3 cells, the ratio only increased to 2.73 at $24 \mathrm{~h}$ (Figure 4C). A similar FRET change in the $2^{\text {nd }}$ generation conjugate (2P-Cy3-Cy5) was also observed (Figure S3). There was significant difference in the release efficacy between cancer and normal cells. This observation suggests an effective release of Cy3 from the conjugate, which is highly dependent on the cathepsin B level. Compared to normal cells, cathepsin B level is much higher in malignant tumors, such as ovarian cancer, breast cancer, melanoma, etc. It acts as an important proteinase of matrix materials to degrade surrounding proteins and other tissue components so that cancer cells can invade and metastasize [47]. Therefore, high expression of cathepsin B in tumor cells can induce a fast release of drugs from conjugates and thereby mediates a relatively high concentration of active free drug inside the tumor cells.
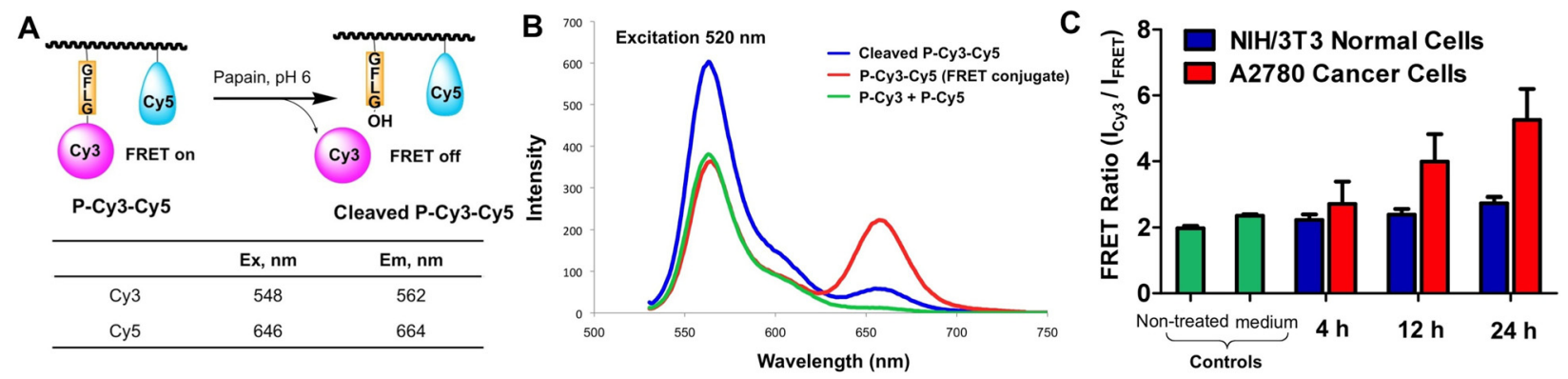

Figure 4. (A) Cartoon illustration of FRET principle of dual-labeled enzyme-cleavable polymer conjugates containing Cy3 (donor) and Cy5 (acceptor). (B) Fluorescence spectra of conjugate $\mathrm{P}-\mathrm{Cy} 3-\mathrm{Cy} 5$ before and after cleavage by papain. The mixture of conjugates P-Cy5/P-Cy3 was measured as control (excitation $520 \mathrm{~nm}$ using methanol as solvent). (C) FRET ratios of P-Cy3Cy5 in NIH3T3 mouse fibroblast cells (low cathepsin B expression) and A2780 ovarian cancer cells (high cathepsin B expression) at different time intervals. The cells were incubated with PCy3-Cy5 at $37^{\circ} \mathrm{C}$ for $4 \mathrm{~h}$ and then cultured in fresh medium for another 0,8 , or $20 \mathrm{~h}$. Then cell lysis was measured by fluorescence spectroscopy. FRET ratio $=I_{\text {Cy } 3} / I_{F R E T}$, was calculated to quantify the FRET change, where $\mathrm{I}_{\mathrm{Cy} 3}$ and $\mathrm{I}_{\mathrm{FRET}}$ are the fluorescence intensity at $562 \mathrm{~nm}$ and $664 \mathrm{~nm}$, respectively (excitation $520 \mathrm{~nm}$ ). Increase of the ratio revealed effective payload release following enzyme exposure.

The conjugate P-Cy3-Cy5 was also evaluated using FRET confocal microscopy, which is a more straightforward approach for performing FRET. In this experiment, pre-bleach and postbleach images were collected. To do the photobleaching, the cells were exposed to high excitation intensity at an excitation wavelength of $646 \mathrm{~nm}$ (Ex of Cy5) for a 20 min period. After high-energy laser treatment, there was a dramatic reduction of Cy5 intensity in the bleached regions (Figure 5). In the cells immediately following $4 \mathrm{~h}$ incubation, it was found that bleaching the acceptor Cy5 resulted in FRET intensity significantly decreased, and donor Cy3 fluorescence substantial increase, because the acceptor can no longer accept energy from the donor. However, those intensity changes did not occur in the same batch of cells after additional $20 \mathrm{~h}$ culture (Figure 5). It indicated that the model drug Cy3 had been released from the backbone after cellular internalization and lysosomal cleavage.

Following the same principle, we synthesized the conjugate P-EPI-Cy5 (Scheme 3). The conjugate was characterized using FRET spectra. The cell uptake and the drug EPI release were determined by FRET intensity changes. In A2780 cancer cells, the ratio decreased from 0.89 (initial stock) to 0.84 at $4 \mathrm{~h}$ and gradually decreased to 0.77 at $24 \mathrm{~h}$ (Figure 6). The reduction of FRET ratio indicates that EPI molecules could be released from the conjugate inside A2780 cancer cells over time. These results showed potential to use FRET as a tool for 
future in vivo real-time monitoring drug delivery, tracking chain scission of HPMA copolymerdrug conjugates, and for improved cancer diagnostics and therapy.

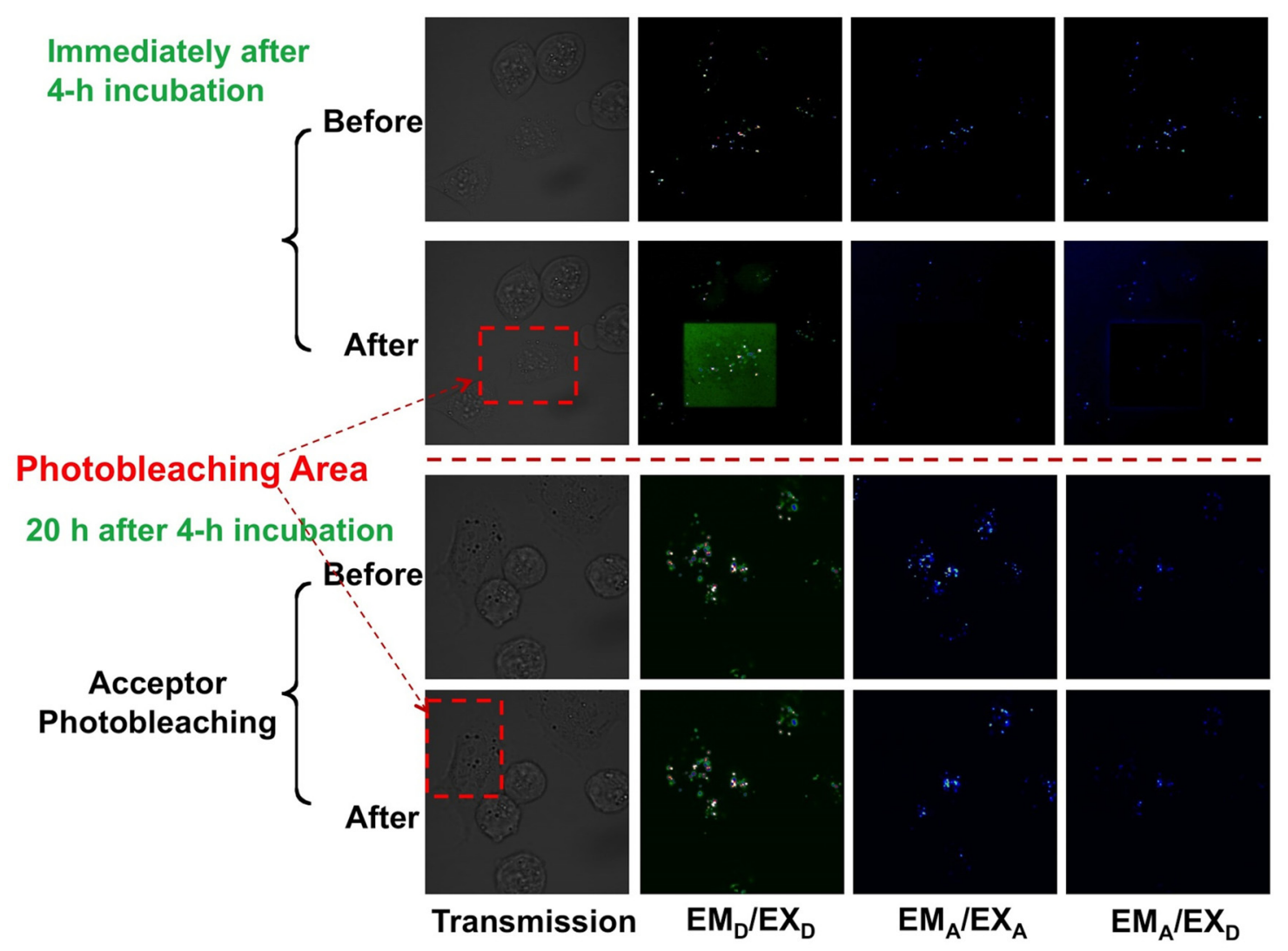

Figure 5. Visualization of payload Cy3 release from conjugate P-Cy3-Cy5 in cathepsin B overexpressing A2780 human ovarian cancer cells by FRET. The cells were first incubated with PCy3-Cy 5 at $37^{\circ} \mathrm{C}$ for $4 \mathrm{~h}$ and then were washed. Half of the cells were fixed immediately, while the other half were incubated with fresh medium at $37^{\circ} \mathrm{C}$ for another $20 \mathrm{~h}$ and fixed. The fixed cells were observed under confocal microscope using the standard acceptor Cy5 photobleaching method. Bleached areas are indicated by red boxes. Representative images of pre- and post-bleaching are shown.
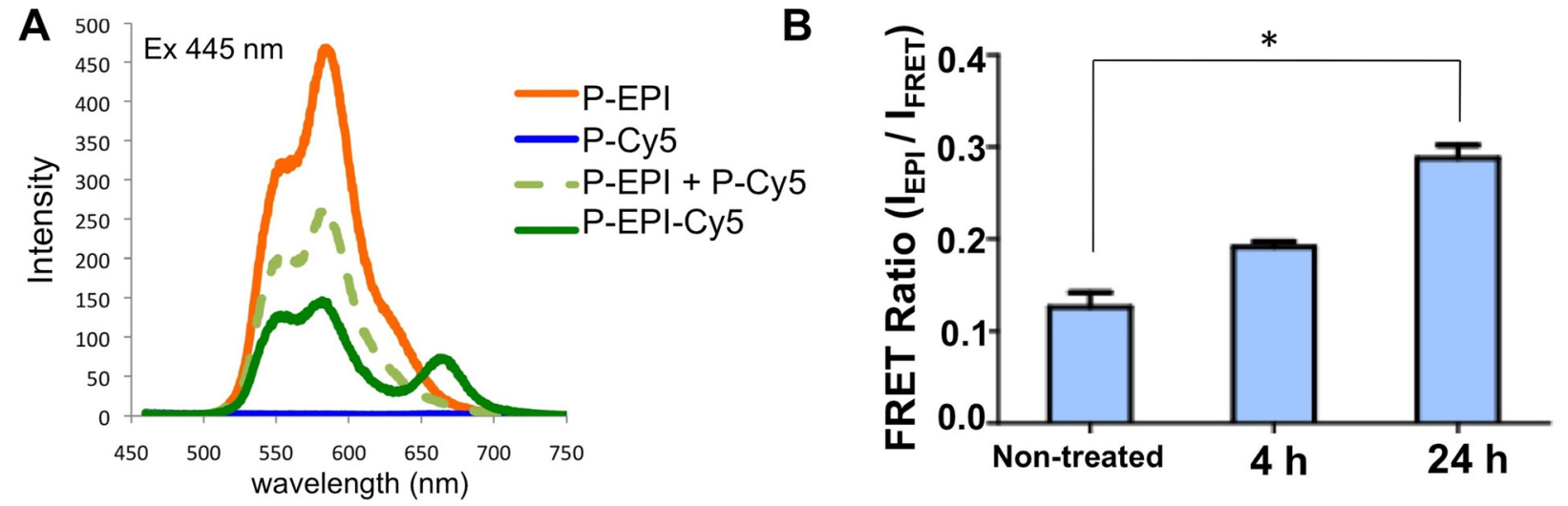

Figure 6. (A) Fluorescence spectra of FRET conjugate P-EPI-Cy5 compared with P-EPI, P-Cy5 and their mixture P-Cy5+P-EPI. (B) The change in FRET ratio of P-EPI-Cy5 conjugate revealed effective EPI release in A2780 ovarian cancer cells. The cathepsin B over-expressing A2780 
cells were incubated with P-EPI-Cy5 at $37^{\circ} \mathrm{C}$ for $4 \mathrm{~h}$ and then were cultured in fresh medium for another $20 \mathrm{~h}$. Then cell lysates at different time intervals were measured by fluorescence spectrometer. FRET ratio $=I_{E P I} / I_{F R E T}$, where $I_{E P I}$ and $I_{F R E T}$ are the fluorescence intensity at 590 $\mathrm{nm}$ and $664 \mathrm{~nm}$, respectively (excitation $490 \mathrm{~nm}$ ). The data are presented as mean \pm standard deviation $(n=3) .{ }^{*}, p<0.01$.

\section{Conclusions}

We have developed a biodegradable polymeric drug delivery system with the capacity for non-invasive fate monitoring using FRET-based methodology. Epirubicin served as both fluorescence donor and antineoplastic agent. The degradable diblock HPMA copolymer-EPI conjugate (2P-EPI) produced complete tumor remission and long-term inhibition of tumorigenesis (100 days) when treating mice bearing human ovarian carcinoma A2780 xenografts. This and PK data provide strong evidence that $2^{\text {nd }}$ generation backbone degradable HPMA copolymer-drug conjugates remarkably enhance circulation time and treatment efficacy. Moreover, in vitro cell uptake and intracellular drug release determined via FRET intensity changes clearly demonstrated cathepsin B levels are decisive and responsible for drug antitumor activity. This aspect will be further investigated ex vivo and in vivo using near-infrared FRET pairs to ensure deeper tissue penetration and better imaging quality.

\section{Acknowledgement}

The research was supported in part by Department of Defense Grant W81XWH-13-1-0160 and $\mathrm{NIH}$ grant CA156933.

\section{References}

[1] C. De Duve, T. De Barsy, B. Poole, A. Trouet, P. Tulkens, F. van Hoof, Lysosomotropic agents, Biochem. Pharmacol. 23 (1974) 2495-2531.

[2] H. Ringsdorf, Structure and properties of pharmacologically active polymers, J. Polym. Sci., Polym. Symp. 51 (1975) 135-153.

[3] J. Kopeček, Polymer - drug conjugates: Origins, progress to date and future directions, Adv. Drug Deliv. Rev. 65 (2013) 49-59.

[4] J. Yang, J. Kopeček, Macromolecular therapeutics, J. Control. Release 190 (2014) 288303.

[5] Y. Zhou, J. Kopeček, Biological rationale for the design of polymeric anti-cancer nanomedicines, J. Drug Target. 21 (2013) 1-26.

[6] H. Maeda, Tumor-selective delivery of macromolecular drugs via the EPR effect: background and future prospects, Bioconjugate Chem. 21 (2010) 797-802.

[7] T. Minko, P. Kopečková, J. Kopeček, Comparison of the anticancer effect of free and HPMA copolymer-bound adriamycin in human ovarian carcinoma cells, Pharmaceutical Res. 16 (1999) 986-996.

[8] P.A. Vasey, S.B. Kaye, R. Morrison, C. Twelves, P. Wilson, R. Duncan, A.H. Thomson, L.S. Murray, T.E. Hilditch, T. Murray, S. Burtles, D. Fraier, E. Frigerio, J. Cassidy, and on behalf of the Cancer Research Campaign Phase I/II Committee, Phase I clinical and pharmacokinetic study of PK1 [N-(2-hydroxypropyl)methacrylamide copolymer doxorubicin]: first member of a new class of chemotherapeutic agents-drug-polymer conjugates, Clin. Cancer Res. 5 (1999) 83-94.

[9] C. Li, S. Wallace, Polymer-drug conjugates: Recent development in clinical oncology, Adv. Drug Delivery Rev. 60 (2008) 886-898. 
[10] R. Duncan, M.J. Vicent, Polymer therapeutics - prospects for $21^{\text {st }}$ century: the end of the beginning, Adv. Drug Deliv. Rev. 65 (2013) 60-70.

[11] P. Chytil, E. Koziolová, O. Janoušková, L. Kostka, K. Ulbrich, T. Etrych, Synthesis and properties of star HPMA copolymer nanocarriers synthesised by RAFT polymerisation designed for selective anticancer drug delivery and imaging, Macromolecular Bioscience 15 (2015) 839-850

[12] P. Chytil, S. Hoffmann, L. Schindler, L. Kostka, K. Ulbrich, H. Caysa, T. Mueller, K. Mäder, T. Etrych, Dual fluorescent HPMA copolymers for passive tumor targeting with pHsensitive drug release II: Impact of release rate on biodistribution, J. Control. Release 172 (2013) 504-512.

[13] J. Yang, K. Luo, H. Pan, P. Kopečková, J. Kopeček, Synthesis of biodegradable multiblock copolymers by click coupling of RAFT-generated heterotelechelic polyHPMA conjugates, Reactive Functional Polym. 71 (2011) 294-302.

[14] K. Luo, J. Yang, P. Kopečková, J. Kopeček, Biodegradable multiblock N-(2hydroxypropyl)methacrylamide copolymers via reversible addition-fragmentation chain transfer polymerization and click chemistry, Macromolecules 44 (2011) 2481-2488.

[15] H. Pan, J. Yang, P. Kopečková, J. Kopeček, Backbone degradable multiblock N-(2hydroxypropyl)methacrylamide copolymer conjugates via reversible addition-fragmentation chain transfer polymerization and thiol-ene coupling reaction, Biomacromolecules 12 (2011) 247-252.

[16] R. Zhang, J. Yang, M. Sima, Y. Zhou, J. Kopeček, Sequential combination therapy of ovarian cancer with degradable $\mathrm{N}$-(2-hydroxypropyl)methacrylamide copolymer paclitaxel and gemcitabine conjugates, Proc. Natl. Acad. Sci. USA 111 (2014) 12181-12186.

[17] R. Zhang, K. Luo, J. Yang, M. Sima, Y. Sun, M.M. Janát-Amsbury, J. Kopeček, Synthesis and evaluation of a backbone biodegradable multiblock HPMA copolymer nanocarrier for the systemic delivery of paclitaxel, J. Control. Release 166 (2013) 66-74.

[18] H. Pan, M. Sima, J. Yang, J. Kopeček, Synthesis of long-circulating backbone degradable HPMA copolymer-doxorubicin conjugates and evaluation of molecular weight dependent antitumor efficacy, Macromol. Biosci. 13 (2013) 155-160.

[19] H. Pan, M. Sima, S.C. Miller, P. Kopečková, J. Yang, J. Kopeček, Promotion of bone formation in ovariectomized rats by high molecular weight backbone degradable HPMA copolymer - prostaglandin $\mathrm{E}_{1}$ conjugate, Biomaterials 34 (2013) 6528-6538.

[20] S.V. Ontrust, L.R. Wiseman, K.L. Goa, Epirubicin: A review of its intravesical use in superficial bladder cancer, Drugs Aging 15 (1999) 307-333.

[21] H. Havsteen, K. Bertelsen, C.C. Gadeberg, A. Jacobsen, C. Kamby, E. Sandberg, L. Sengelov, A phase 2 study with epirubicin as second-line treatment of patients with advanced epithelial ovarian cancer, Gynecol. Oncol. 63 (1996) 210-215.

[22] G.L. Plosker, D. Faulds, Epirubicin: A review of its pharmacodynamic and pharmacokinetic properties, and therapeutic use in cancer chemotherapy, Drugs 45 (1993) 788-856.

[23] M. Marquez, J. Du, M. Edgren, S. Nilsson, L. Lennartsson, J. Hiltunen, J.E. Westlim, T. Tammela, M. Raitanen, M. Laato, G. Jönsson, A.R. Holmberg, Development of dextran derivatives with cytotoxic effects in human urinary cancer cell lines, Anticancer Res. 22 (2002) 741-744.

[24] F. Canal, M.J. Vicent, G. Pasut, O. Schiavon, Relevance of folic acid/polymer ratio in targeted PEG-epirubicin conjugates, J. Control. Release 146 (2010) 388-399.

[25] G. Pasut, S. Scaramuzza, O. Schiavon, R. Mendichi, F.M. Veronese, PEG-epirubicin conjugates with high drug loading, J. Bioact. Compat. Polym. 20 (2005) 213-230.

[26] H. Takahashi, K. Adachi, F. Yamaguchi, A. Teramoto, Experimental treatment of malignant gliomas with human monoclonal antibody-drug conjugates, Anticancer Res. 19 (1999) 4151-4155.

[27] B. Ríhová, Clinical experience with anthracycline antibiotics-HPMA copolymer-human 
immunoglobulin conjugates, Adv. Drug Deliv. Rev. 61 (2009) 1149-1158.

[28] F. Greco, I. Arif, R. Botting, C. Fante, L. Quintieri, C. Clementi, O. Schiavon, G. Pasut, Polysialic acid as drug carrier: Evaluation of a new polysialic acid-epirubicin conjugate and its comparison against established drug carriers, Polym. Chem. 4 (2013) 1600-1609.

[29] J. Kopeček, H. Bažilová, Poly[N-(2-Hydroxypropyl)methacrylamide]. 1. Radical polymerization and copolymerization, Eur. Polym. J. 9 (1973) 7-14.

[30] J. Kopeček, P. Rejmanová, J. Strohalm, K. Ulbrich, B. Rihova, V. Chytry, J.B. Lloyd, R. Duncan, Synthetic polymeric drugs. US Patent 5,037,883 (1991).

[31] V. Šubr, K. Ulbrich, Synthesis and properties of new $\mathrm{N}$-(2-hydroxypropyl)methacrylamide copolymers containing thiazolidine-2-thione reactive groups, Reactive Functional Polym. 66 (2006) 1525-1538.

[32] R. Duncan, H.C. Cable, P. Rejmanová, J. Kopeček, J.B. Lloyd, Tyrosinamide residues enhance pinocytic capture of $N$-(2-hydroxypropyl)methacrylamide copolymers, Biochim. Biophys. Acta 799 (1984) 1-8.

[33] Y. Mitsukami, M. S.Donovan, A. B. Lowe, C. L. McCormick, Water-soluble polymers. 81. Direct synthesis of hydrophilic styrenic-based homopolymers and block copolymers in aqueous solution via RAFT, Macromolecules 34 (2001) 2248-2256.

[34] Y.L. Chiu, S.A. Chen, J.H. Chen, K.J. Chen, H.L. Chen, H.W. Sung, A dual-emission fo"rster resonance energy transfer nanoprobe for sensing/lmaging $\mathrm{pH}$ Changes in the Biological environment, ACS Nano 4 (2012), 7467-7474.

[35] G.N. Hortobagyi, H.Y. Yap, S.W. Kau, G. Franchini, M.S. Ewer, S.P. Chawla, R. Benjamin, A comparative study of doxorubicin and epirubicin in patients with metastatic breast cancer, Am. J. Clin. Oncol. 12 (1989) 57-62.

[36] Y. Yamamoto, I.Hyodo, Y. Koga, R. Tsumura, R.Sato,T.Obonai, H. Fuchigami, F. Furuya, M. Yasunaga, M.Harada, Y. Kato, A. Ohtsu, Y. Matsumura, Enhanced antitumor effect of anti-tissue factor antibody-conjugated epirubicin-incorporating micelles in xenograft models. Cancer Sci 106 (2015) 627-634.

[37] Q. Yang, T. Zhang, C. Wang, J. Jiao, J. Li, Y. Deng, Coencapsulation of epirubicin and metformin in PEGylated liposomes inhibits the recurrence of murine sarcoma $\mathrm{S} 180$ existing CD133+ cancer stem-like cells, Eur J Pharm Biopharm. 88, (2014) 737-745.

[38] M. Tariq, M.A. Alam, A.T. Singh, Z. Iqbal, A.K. Panda, S. Talegaonkar, Biodegradable polymeric nanoparticles for oral delivery of epirubicin: In vitro, ex vivo, and in vivo investigations, Colloids Surf B Biointerfaces 128 (2015) 448-456.

[39] X. Wang, X.C. Low, W.Hou, L.N. Abdullah, T.B. Toh, M.M.A. Rashid, D. Ho, E.K.H. Chow, Epirubicin-adsorbed nanodiamonds kill chemoresistant hepatic cancer stem cells, ACS Nano 8 (2014) 12151-12166.

[40] L. Seymour, K. Ulbrich, J. Strohalm, J. Kopeček, R. Duncan, The Pharmacokinetics of Polymer-Bound Adriamycin, Biochem Pharmacol 39 (1990) 1125-1131.

[41] S. Fogli, R. Danesi, A. Gennari, S. Donati, P. F. Conte, M. Del Tacca, Gemcitabine, epirubicin and paclitaxel: pharmacokinetic and pharmacodynamic interactions in advanced breast cancer, Annals of Oncology 13 (2002) 919-927.

[42] Y. Zhou, J. Yang, J. Rhim, J. Kopeček, HPMA copolymer-based combination therapy toxic to both prostate cancer stem/progenitor cells and differentiated cells induces durable antitumor effects, J. Controlled Release 172 (2013) 946-953

[43] I. Matai, A. Sachdev, P. Gopinath, Self-assembled hybrids of fluorescent carbon dots and PAMAM dendrimers for epirubicin delivery and intracellular imaging, ACS Appl. Mater. Interfaces Ahead of Print (2015).

[44] S. J. Hauff, S. C. Raju, R. K. Orosco, A. M. Gross, J. A. Diaz-Perez, E. Savariar, N. Nashi, J. Hasselman, M. Whitney, J. N. Myers, S. M. Lippman, R. Y. Tsien, T. Ideker, and Q. T. Nguyen, 'Matrix-Metalloproteinases in Head and Neck Carcinoma-Cancer Genome Atlas 
Analysis and Fluorescence Imaging in Mice', Otolaryngol Head Neck Surg, 151 (2014), 612-8.

[45] T. Hussain, E. N. Savariar, J. A. Diaz-Perez, K. Messer, M. Pu, R. Y. Tsien, and Q. T. Nguyen, 'Surgical Molecular Navigation with Ratiometric Activatable Cell Penetrating Peptide for Intraoperative Identification and Resection of Small Salivary Gland Cancers', Head Neck (2015) DOI: 10.1002/hed.23946.

[46] E. N. Savariar, C. N. Felsen, N. Nashi, T. Jiang, L. G. Ellies, P. Steinbach, R. Y. Tsien, and Q. T. Nguyen, 'Real-Time in Vivo Molecular Detection of Primary Tumors and Metastases with Ratiometric Activatable Cell-Penetrating Peptides', Cancer Res, 73 (2013), 855-64.

[47] H, Nishikawa, Y. Ozaki, T. Nakanish, K. Blomgren, T. Tada, A. Arakawa, K. Suzumori, The role of cathepsin B and cystatin $\mathrm{C}$ in the mechanisms of invasion by ovarian cancer, Gynecol

Oncol.
92
881-886. 
Table, Scheme and Figure captions

Table 1. Characterization of HPMA copolymer-epirubicin conjugates

Table 2. Comparison of pharmacokinetic parameters for ${ }^{125} \mathrm{I}$-labeled conjugates in mice

Scheme 1. Synthesis of HPMA copolymer-epirubicin conjugates

Scheme 2. Synthesis of polymer conjugates containing fluorophores

Scheme 3. Synthesis of polymer conjugates containing epirubicin and Cy5 (P-EPI-Cy5)

Figure 1. Cell uptake and cytotoxicity of free drug EPI and its conjugates (P-EPI, 2P-EPI) in A2780 human ovarian cancer cells. (A) Flow cytometry analysis of cell uptake in the A2780 cells incubated with medium alone (non-treated), free EPI, or its conjugates (P-EPI, 2P-EPI) at $37{ }^{\circ} \mathrm{C}$ for 6 and $24 \mathrm{~h}$. MFI, mean fluorescence intensity. (B) In vitro cytotoxicity of free drug EPI and its HPMA conjugates (PEPI, 2P-EPI) toward A2780 human ovarian carcinoma cells. The data are presented as mean \pm standard deviation $(n=3-4)$.

Figure 2. Pharmacokinetic profiles of ${ }^{125}$-labeled conjugates P-EPI and $2 \mathrm{P}$-EPI in mice. The data represent the mean radioactivity expressed as a percentage of the injected dose per gram of blood $(n=5)$.

Figure 3. Comparison of in vivo anti-tumor activity on female nude mice bearing A2780 human ovarian carcinoma xenografts. (A) The mice were intravenously injected with 3 doses of EPI or HPMA copolymer-EPI conjugates (P-EPI and 2P-EPI). Free drug and untreated groups were stopped on day 20 due to large size of tumors. (B) Long-term monitoring of tumor growth in conjugate treatments. (C) The tumor size on day 80 of the polymer conjugates, and (D) End point photographs of tumor-bearing mice from variable treatments.

Figure 4. (A) Cartoon illustration of FRET principle of dual-labeled enzyme-cleavable polymer conjugates containing Cy3 (donor) and Cy5 (acceptor). (B) Fluorescence spectra of conjugate P-Cy3-Cy5 before and after cleavage by papain. The mixture of conjugates $\mathrm{P}-\mathrm{Cy} 5 / \mathrm{P}-\mathrm{Cy} 3$ was measured as control (excitation $520 \mathrm{~nm}$ using methanol as solvent). (C) FRET ratios of P-Cy3-Cy5 in NIH3T3 mouse fibroblast cells (low cathepsin B expression) and A2780 ovarian cancer cells (high cathepsin B expression) at different time intervals. The cells were incubated with P-Cy3-Cy5 at $37^{\circ} \mathrm{C}$ for $4 \mathrm{~h}$ and then cultured in fresh medium for another 0,8 , or $20 \mathrm{~h}$. Then cell lysis was measured by fluorescence spectroscopy. FRET ratio $=\mathrm{I}_{\mathrm{Cy}} / \mathrm{I}_{\mathrm{FRET}}$, was calculated to quantify the FRET change, where $I_{\mathrm{Cy}}$ and $I_{\mathrm{FRET}}$ are the fluorescence intensity at $562 \mathrm{~nm}$ and $664 \mathrm{~nm}$, respectively (excitation $520 \mathrm{~nm}$ ). Increase of the ratio revealed effective payload release following enzyme exposure. 
Figure 5. Visualization of payload Cy3 release from conjugate P-Cy3-Cy5 in cathepsin B over-expressing A2780 human ovarian cancer cells by FRET. The cells were first incubated with P-Cy3-Cy5 at $37^{\circ} \mathrm{C}$ for $4 \mathrm{~h}$ and then were washed. Half of the cells were fixed immediately, while the other half were incubated with fresh medium at $37^{\circ} \mathrm{C}$ for another $20 \mathrm{~h}$ and fixed. The fixed cells were observed under confocal microscope using the standard acceptor Cy5 photobleaching method. Bleached areas are indicated by red boxes. Representative images of pre- and post-bleaching are shown.

Figure 6. (A) Fluorescence spectra of FRET conjugate P-EPI-Cy5 compared with P-EPI, $\mathrm{P}-\mathrm{Cy} 5$ and their mixture P-Cy5+P-EPI. (B) The change in FRET ratio of P-EPICy5 conjugate revealed effective EPI release in A2780 ovarian cancer cells. The cathepsin B over-expressing A2780 cells were incubated with P-EPI-Cy5 at $37^{\circ} \mathrm{C}$ for $4 \mathrm{~h}$ and then were cultured in fresh medium for another $20 \mathrm{~h}$. Then cell lysates at different time intervals were measured by fluorescence spectrometer. FRET ratio $=I_{\text {EPI }} / I_{F R E T}$, where $I_{\text {EPI }}$ and $I_{\text {FRET }}$ are the fluorescence intensity at 590 $\mathrm{nm}$ and $664 \mathrm{~nm}$, respectively (excitation $490 \mathrm{~nm}$ ). The data are presented as mean \pm standard deviation $(n=3)$. ${ }^{*}, p<0.01$. 

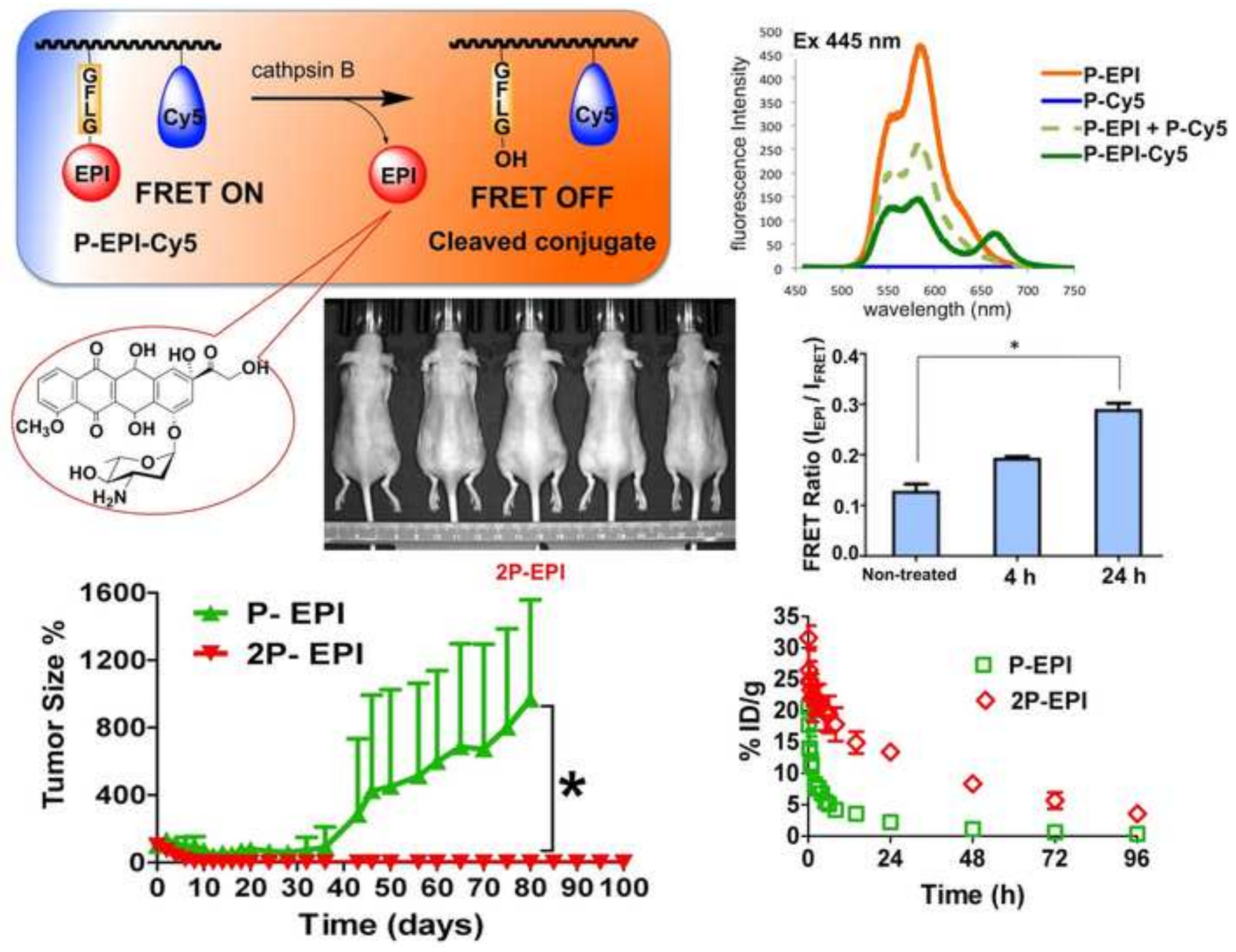